\title{
Microstructure and Strain Rate Sensitivity of Mg-11Li-3Al-1Ca Alloy
}

\author{
L. R. Cheng, Z. Y. Cao*, Y. B. Liu, L. Zhang, T. Q. Li and G. H. Su \\ Key Laboratory of Automobile Materials of Ministry of Education, Department of Materials Science and Engineering, \\ Jilin University, 5988 Renmin Street, Changchun 130025, P. R. China
}

As-cast and extruded Mg-11Li-3Al-1Ca alloys were successfully prepared. The microstructure of specimens was analyzed with OM, SEM, EDS and XRD. It was found that as-cast specimens were composed of $\beta$ phase (Lithium), small pieces of divorced eutectic $\alpha$ phase (Magnesium), $\mathrm{MgLi}_{2} \mathrm{Al}$ and $\mathrm{Al}_{2} \mathrm{Ca}$ compounds. During the extrusion process, the microstructure was refined and partial recrystallization was observed. Uniaxial tension tests were carried out under different strain rate. The ultimate intensities were obviously higher than common $\beta$ phase $\mathrm{Mg}-\mathrm{Li}$ alloys to compare with past studies. Deformation capacity of the extruded specimen at room temperature was estimated by strain-rate sensitivity exponent ( $m$ value), which was 0.071 . Serrated flows were apparent through out the deformation history and the phenomenon was interpreted through the competition between dynamic strain aging (DSA) of solute atoms and shearing of precipitates by dislocations. [doi:10.2320/matertrans.M2010231]

(Received July 12, 2010; Accepted September 10, 2010; Published November 25, 2010)

Keywords: magnesium-lithium alloy, microstructure, mechanical properties, strain rate sensitivity

\section{Introduction}

Magnesium-lithium alloys are the lightest known metallic structural materials and even attractive for secondary structural or non structural materials for aerospace, missile and armor applications. ${ }^{1,2)}$ The mechanical properties and material plastic forming of $\mathrm{Mg}-\mathrm{Li}$ alloys at room temperature have long been investigated. Lithium addition to magnesium has an important effect on the lattice parameters. ${ }^{3)}$ The addition of lithium to magnesium with greater than about 11 mass \% (30 at \%) causes the crystal structure to transform from hcp $\alpha$ phase to single bcc $\beta$ phase. The bcc $\beta$ phase is soft and ductile, which allows the magnesium alloys to be used in cold-work. Hence, the content of 11 mass $\%$ is a special point that worth to be studied.

In the present work, the lithium content is designed at the point contact of lithium single-phase region in the $\mathrm{Mg}-\mathrm{Li}$ equilibrium phase diagram. Our present $\mathrm{Mg}-11 \mathrm{Li}-3 \mathrm{Al}-1 \mathrm{Ca}$ alloy has the higher stiffness than some of dual phase $\mathrm{Mg}-\mathrm{Li}$ alloys. ${ }^{4,5)}$ It is proposed that the room temperature stiffness of the extruded $\mathrm{Mg}-11 \mathrm{Li}-3 \mathrm{Al}-1 \mathrm{Ca}$ alloy can be enhanced by dispersed fine compounds and grains refinement. Further, the formability of the extruded alloy at room temperature is investigated by uniaxial tension test with different strain rate ranging from $10^{-4}$ to $10^{-2} \mathrm{~S}^{-1}$. The strain-rate sensitivity exponent ( $m$ value), is evaluated to be 0.078 .

\section{Experimental Procedure}

The as-cast $\mathrm{Mg}-8 \mathrm{Li}-3 \mathrm{Al}-1 \mathrm{Ca}$ alloy was melted in vacuum melting furnace with argon atmosphere. Uniform heat treatment was carried out at $573 \mathrm{~K}(10 \mathrm{~h})$ in the vacuum heat treatment furnace. After heat treatment, the specimens were extruded at $493 \mathrm{~K}$ from $\Phi 50 \mathrm{~mm}$ to $\Phi 14 \mathrm{~mm}$ with a constant speed of $2.0 \mathrm{~m} / \mathrm{min}$. Induction coupled plasma (ICP) apparatus X Series II ICP-MS was used to test the alloy components, as shown in Table 1. Microstructural and phase information were obtained by a combination of Olympus

*Corresponding author, E-mail: zycao@jlu.edu.cn
Table 1 The ICP test results.

\begin{tabular}{ccccc}
\hline Element compositions & mass\% Li & mass\% $\mathrm{Al}$ & mass\% Ca & mass\% $\mathrm{Mg}$ \\
\hline Mg-11Li-3Al-1Ca & 10.91 & 3.213 & 0.8229 & Bal.
\end{tabular}

OLS 3000 scanned-laser microscope, scanning electron microscopy (SEM) with energy dispersive spectroscopy (EDS), and X-ray diffraction (XRD). Lattice parameters were calculated by stepping XRD. Uniaxial tensile tests were performed on MTS-810 system (MTS, US), with initial strain rate ranging from $1.0 \times 10^{-4}$ to $0.01 \mathrm{~s}^{-1}$.

\section{Result and Discussion}

\subsection{Microstructure and composition of alloys}

Figure 1 shows XRD patterns from the as-cast and extruded Mg-11Li-3Al-1-Ca alloy. The patterns show that the basic micro-structural constituents are $\beta$ phase (Lithium). Small peaks of $\mathrm{MgLi}_{2} \mathrm{Al}$ and $\mathrm{Al}_{2} \mathrm{Ca}$ intermetallic phases are identifiable. A small quantity of hcp $\alpha$ phase (Magnesium) had also been confirmed. The microstructures of as-cast and extruded specimens are shown in Fig. 2. For the as-cast specimen in Fig. 2(a), the average grain size of bcc $\beta$ phase ranges from $80 \mu \mathrm{m}$ to $150 \mu \mathrm{m}$. Most of the precipitates disperse evenly in the grains. For the lithium content is designed at the point contact of 11 mass $\%$, small pieces of the non-equilibrium solidification $\alpha$ phase are found at the region of grain boundary. Figure 2(b) demonstrates that extruded structures exhibit fibrous extruding textures, which are typical plastically deformed structures. The $\alpha / \beta$ interface orientation relationship was observed by $\mathrm{M}$. V. Kral as $[0001]_{\alpha} / /[0 \overline{1} 1]_{\beta},(\overline{1} 100)_{\alpha} / /(\overline{2} 11)_{\beta}{ }^{6)}$ This means that screw components of the basal dislocations in $\alpha$ phase can move to adjacent slip plane in $\beta$ phase at the appropriate stress state in $\alpha / \beta$ dual phase $\mathrm{Mg}$-Li alloys. However, different from the situation in the dual phases alloy, small pieces of $\alpha$ phases with dispersed compounds in this alloy enhance the distortion of lattice at the region of grain boundaries. The factor of co-deformation mechanism between $\alpha$ and $\beta$ dual phase is 


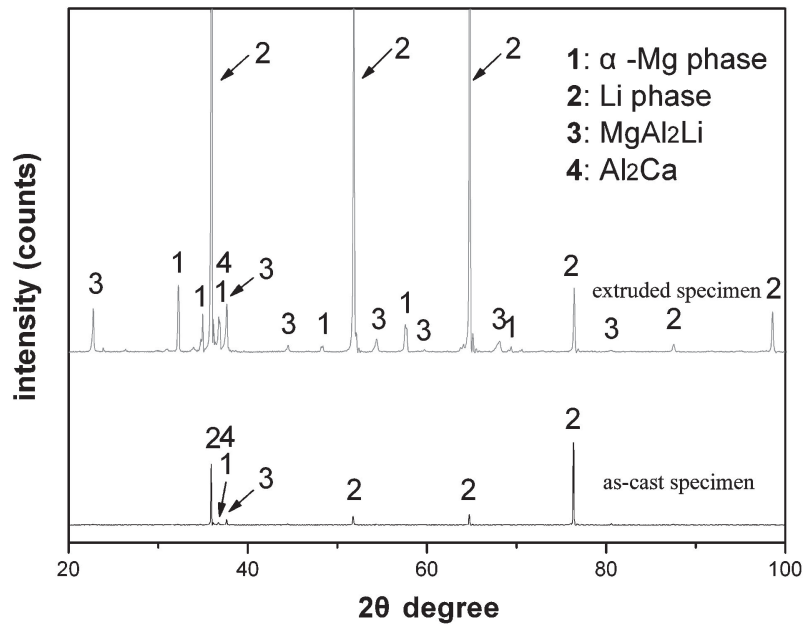

Fig. 1 XRD patterns of Mg-11Li-3Al-1Ca alloys.
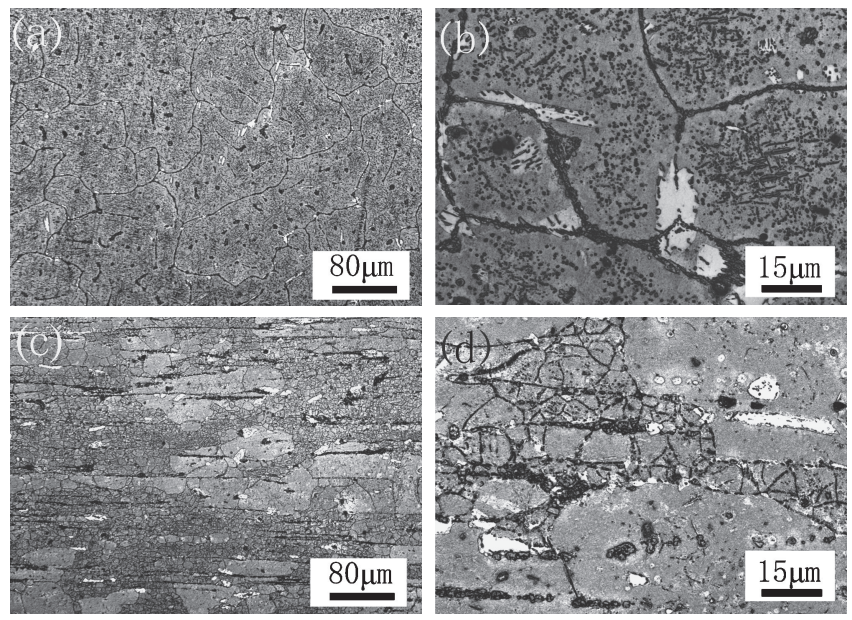

Fig. 2 Microstructure of Mg-11Li-3Al-1Ca alloys. (a) as-cast specimen; (b) local magnification of (a); (c) Parallel to extruding derection; (d) local magnification of (c).

harder to be activated. The $\alpha$ phases may becomes obstacle of dislocations movement rather than co-deformation medium and the intensity of this Mg-8Li-3Al-1Ca increased. Recrystallization partially occurred and $\alpha$ phase located at the grain boundaries. However, for the restriction of extrusion technology, the stress distribution may be not uniform in some parts of one pass extrusion processed specimen. During extrusion process, in the area of stress concentration, Recrystallization was more likely to occur than other parts. Compared with some fine isometric crystal, some grains size reached up to $50 \mu \mathrm{m}$.

Figure 3 is the result of SEM with EDS for the precipitated compounds. It shows that the dispersed granular precipitates are composed of $\mathrm{Mg}$ and $\mathrm{Al}$ elements. The needle like compounds are composed of $\mathrm{Mg}, \mathrm{Al}$ and $\mathrm{Ca}$ elements, and the atom ration of $\mathrm{Al}$ to $\mathrm{Ca}$ is about 2 to 1 . Subtracting the interference value of the magnesium atom in the matrix, the granular compound had been confirmed as $\mathrm{MgAl}_{2} \mathrm{Li}$ phase and the needle like compound should be $\mathrm{Al}_{2} \mathrm{Ca}$ phase accordingly. Generally speaking, particle sizes in the range of several to thousands of atoms in diameter are effective in

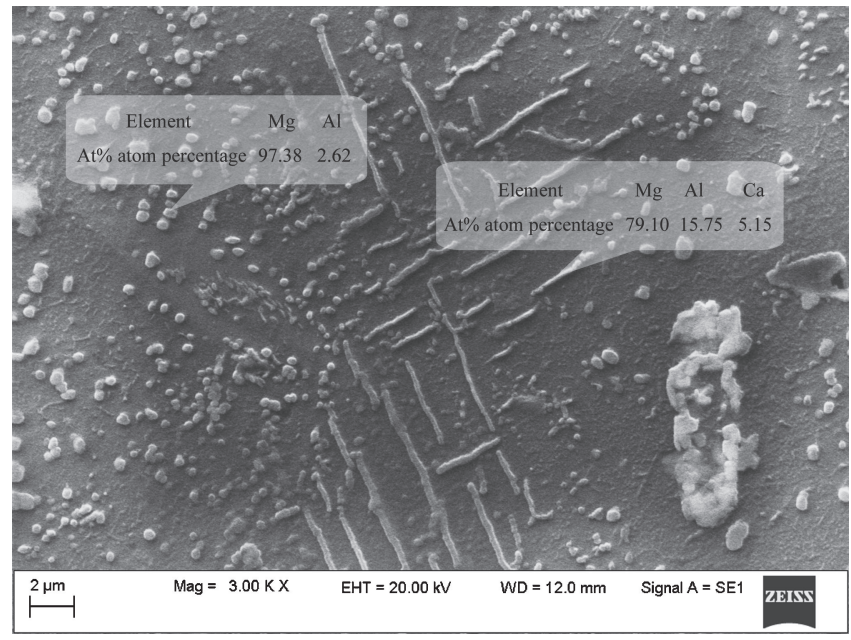

Fig. 3 EDS analysis for the precipitated compound in as-cast specimen.

promoting particle hardening. Particles with sizes greater than this are still effective. As shown in Fig. 3, the average particle size of spherical $\mathrm{MgAl}_{2} \mathrm{Li}$ phases is exactly in this range. ${ }^{7)}$ Many studies have shown that for the $\mathrm{MgAl}_{2} \mathrm{Li}$ particle dimensions, dislocation tend to bow between large particles or between particles with disordered interface boundaries. ${ }^{8,9)}$ So that the $\mathrm{MgAl}_{2} \mathrm{Li}$ phases will obstruct normal motion of dislocation and the strength is improved. Non-spherical particle (e.g., plates and needles) are common to many precipitation hardening alloys and also can be more effective as strengtheners than spherical particles. Hence needle like $\mathrm{Al}_{2} \mathrm{Ca}$ compound is more effective as strengthener than the spherical $\mathrm{MgAl}_{2} \mathrm{Li}$ precipitate.

\subsection{Mechanical properties of specimens}

The mechanical properties of as-cast and extruded specimens are shown in Fig. 4. All the tensile stress-strain curves exhibited the yield points which are corresponding to the bcc structure of the matrix. In Fig. 4(a), the as-cast specimen showed good strength and ductility. After extruding process, the refined grain boundaries constrain are more restrictive to dislocation motion. As shown in Fig. 4(b), the fracture strength, yield strength and elongation are all improved. Magnesium solute atoms concentration in this lithium matrix reaches up to the solid solubility limit. The crystal lattice constant of this $\beta$ Li matrix is calculated to be $0.352327 \mathrm{~nm}$, which is higher than the pure lithium lattice constant of $0.351 \mathrm{~nm}$. Solid-solution strengthening is an important reason for the high yield strength of the Mg-11Li-3Al-1-Ca alloy. Recent studies suggest that LAY831 alloy prepared by extrusion forming has the engineering tensile strength of $210 \mathrm{MPa}$ and elongation of $30 \%$ respectively. ${ }^{4)}$ Comparing with previous studies, this extruded alloy exhibited higher stiffness than many of reported dual phase Mg-Li alloys prepared by extrusion, roll or even ECAP forming methods. ${ }^{10,11)}$ Moreover, it had high coefficient of elongation.

Serrated flows were apparent through out the deformation history. Dynamic strain aging (DSA) of solute atoms would mainly contribute to this phenomenon. This is a result of the interactions that take place between a moving dislocation and solute atoms, especially the maximum interaction which is 

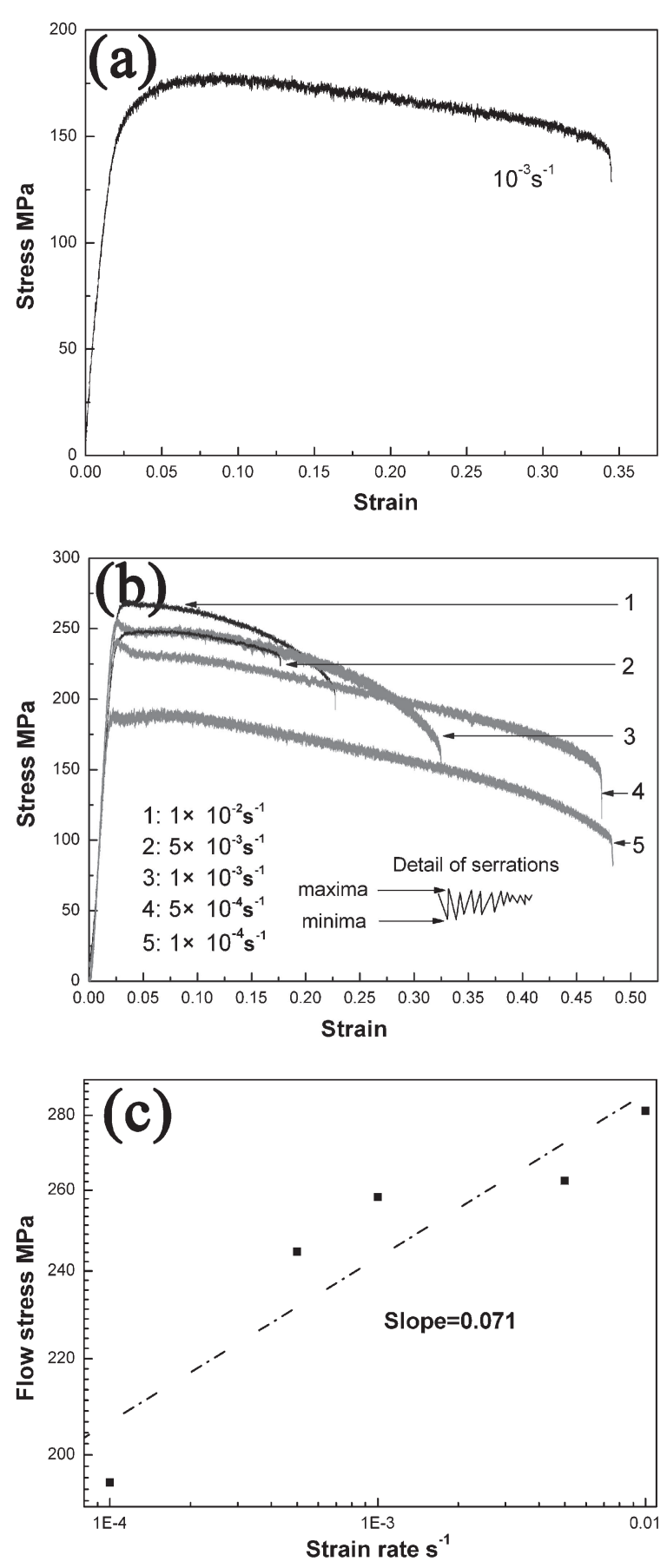

Fig. 4 (a) Engineering stress-strain curves of as-cast specimen under strain rate of $10^{-3} \mathrm{~s}^{-1}$; (b) Engineering stress-strain curves of extruded specimens under different strain rates at $293 \mathrm{~K}$; (c) Logarithm plots of flow stress at $1 \%$ plastic strain $\left(\sigma_{1 \%}\right)$ as a function of strain rate $(\dot{\varepsilon})$ for the $\mathrm{Mg}$ $11 \mathrm{Li}-3 \mathrm{Al}-1 \mathrm{Ca}$ alloy. The strain rate sensitivity ( $m$ value) is estimated from the slope of the linear fit.

experienced with those atoms lying in close proximity to the glide plane. Flow stress consists of two parts: local stress maxima and minima. Local stress maxima correspond to the stresses required to break dislocation away from the solute atoms following them. For this alloy, introduction of the substitutional magnesium solute atoms into the lithium crystal produce the greatest degree of lattice dilation that typically give rise to spherically symmetric stress fields around the solutes. The local stress minima correspond to that stress required to move the dislocation absent the "drag" affect of the solute atoms. After a local minima is obtained, dislocation velocity is temporally reduced and this permits the solute atoms to "catch up" with the moving dislocations. ${ }^{12)}$ These interactions lead to unsteady, collective motion of dislocations within grains and across grain boundaries, which, in turn, cause the observed jerky flow and surface markings.

Coherent boundaries and small particles generally result in dislocations passing through or "cutting" the particles. At the condition of relatively low strain rate, the jerky appearance in the serrated flow is also caused by the dislocation shearing effect. ${ }^{13)}$ With deformation proceeding, substantial piling up of dilocations may cut through fine particles of $\mathrm{MgAl}_{2} \mathrm{Li}$ or passing through it with shear loops, and stress concentration will be relaxed temporarily; repeating shearing will lead to successive stress drops. And then a jerk appearance was obstained in the stress-strain curve. Micromechanism of the interaction of dislocation movement with particles and grain boundaries need further investigation.

The velocity for mobile dislocation and flow stress are in a positively proportion. In the tensile test, the higher stain rate is the larger velocity for mobile dislocation will be, so it is with the flow stress. When the larger strain rate is applied, point defects increase in numbers. The lattice dilation which is produced by point defect is negtive and vice versa for the magnesium solute atoms in lithium matrix. Solute drag effect is assumed in the process of dislocation movement. ${ }^{14)}$ The interaction between point defects and dislocations is more effective in higher strain rate than that of slow dislocations.

Superplastic behavior correlates with a high strain-rate sensitivity exponent, $m$, in the constitutive equation:

$$
\sigma_{T}=K^{\prime}\left(\dot{\varepsilon}_{T}\right)^{m}
$$

Where $\dot{\varepsilon}_{T}$ is the true strain rate, $m$ the strain-rate sensitivity, and $K^{\prime}$ a constant that signifies it is the material flow stress at a true strain rate of unity. There were a number of reasons for the strain-rate sensitivity, and they all related to the microscopic mechanisms of dislocation movement. The value of $m$ are bracketed between 0 and 1. The high value of $m$ is always associated with a greater resistance to neck development and delayed tensile failure, just as do high values of the strainhardening coefficient. For most alloys, the $m$ values range form 0.00 to 0.1 at room temperature. ${ }^{15)}$ The steady-state flow stress at $1 \%$ plastic strain was plotted in logarithmic form as a function of strain rate shown in Fig. 4(c). The $m$ value of Mg$11 \mathrm{Li}-3 \mathrm{Al}-1 \mathrm{Ca}$ alloy is evaluated to be 0.071 , which is a high value for room temperature. Previous studies have shown a thin sheet of Mg-8.5Li-1Zn alloy with good fomability for deep drawing process at room temperature. The results showed that the elongation of the extruded Mg-11Li-3Al-1$\mathrm{Ca}$ alloy approaches the thin sheet and this alloy shows even higher $m$ value than that of $\mathrm{Mg}-8.5 \mathrm{Li}-1 \mathrm{Zn}$ alloy $(m=0.064)$ under uniaxial tension states. ${ }^{16)}$ The work-hardening rate and plastic anisotropy also affect the formability of materials. Future research will focus on these topics.

\section{Conclusions}

(1) In as-cast specimens of $\mathrm{Mg}-11 \mathrm{Li}-3 \mathrm{Al}-1 \mathrm{Ca}$ alloy, the microstructure is composed of $\beta$ phase (Lithium), small piece 
of $\alpha$ phase (Magnesium), dispersed spherical $\mathrm{MgAl}_{2} \mathrm{Li}$ compound and needle like $\mathrm{Al}_{2} \mathrm{Ca}$ compound. After extruding process, the $\beta$ phase (Lithium) is refined. The crystal lattice constant of this $\beta \mathrm{Li}$ matrix is calculated to be $0.352327 \mathrm{~nm}$.

(2) For the reason of refining strengthen effect, the extruded Mg-11Li-3Al-1Ca alloy exhibits attractive mechanical properties. The $m$ value of $\mathrm{Mg}-11 \mathrm{Li}-3 \mathrm{Al}-1 \mathrm{Ca}$ alloy is evaluated to be 0.078 , which is a high value for room temperature.

\section{Acknowledgements}

The project is supported by the Key Laboratory of Superlight Material and Surface Technology (Harbin Engineering University), Ministry of Education, especially professor R. Z. Wu and M. L. Zhang.

\section{REFERENCES}

1) P. Crawford, R. Barrosa, J. Mendez, J. Foyos and O. S. Es-Said: J. Mater. Process. Technol. 56 (1996) 108-118.

2) M. M. Avedesian and H. Baker: ASM Int., (Metal Park, OH, 1999).
3) D. Hardie and R. N. Parkins: Phil. Mag. 4 (1959) 815-825.

4) R. Z. Wu, Z. K. Qu and M. L. Zhang: Mater. Sci. Eng. A 516 (2009) 96-99.

5) T. C. Chang, J. Y. Wang, C. L. Chu and S. Lee: Mater. Lett. 60 (2006) 3272-3276.

6) M. V. Kral, B. C. Muddle and J. F. Nie: Mater. Sci. Eng. A 460 (2007) 227-232.

7) T. H. Courtney: Mechanical Behavior of Materials, (China Machnie Press, 2004) p. 197.

8) P. B. Hirsch and F. J. Humphries: Physics of Strength and Plasticity, ed. by A. Argon, (M.I.T. Press, Cambridge, 1969).

9) R. M. Wang, A. Eliezer and E. M. Gutman: Mater. Sci. Eng. A 355 (2003) 201-207.

10) T. Liu, W. Zhang, S. D. Wu, C. B. Jiang, S. X. Li and Y. B. Xu: Mater. Sci. Eng. A 360 (2003) 345-349.

11) Y. Yoshida, H. Yamada, S. Kamado et al.: J. JFS 51 (2001) 551555.

12) E. Robert and R. Hill: Physical Metallurgy Principles, 2nd ed., D. Van Nostrand, New York, (1973).

13) J. Hirth and J. Lothe: Theory of Dislocations, (Wiley, New York, 1982) p. 575.

14) C. Wang, Y. B. Xu and E. H. Han: Mater. Lett. 60 (2006) 2941-2944.

15) T. H. Courtney: Mechanical Behavior of Materials, (China Machnie Press, 2004) p. 16.

16) H. Takuda, T. Enami, K. Kubota and N. Hatta: J. Mater. Process. Technol. 101 (2000) 281-286. 